\title{
Abordagem diagnóstica e terapêutica da urticária infância
}

\section{Maria Elisa Bertocco Andrade ${ }^{1}$}

Resumo: a urticária é uma doença que acomete criança com particularidades em relação ao diagnóstico e tratamento. Na sua maioria ocorre de forma aguda, mas formas crônicas também são vistas e representam um desafio tanto na identificação da causa como no manejo. Neste artigo de revisão podemos obter informações que auxiliam na condução diagnóstica etiológica esta doença, assim como no seu controle.

Palavras chave:urticaria aguda, urticária crônica,urticária física, infância

Andrade, Maria Elisa Bertocco. "Abordagem diagnóstica e terapêutica da urticária infância", in Anais do 2‥ Congresso Internacional Sabará de Especialidades Pediátricas

${ }^{1-}$ Mestre em Imunologia pela UNIFESP Médica do Serviço de Alergia e Imunologia do IAMSPE e Complexo Hospitalar Padre Bento de Guarulhos.

\section{Introdução}

Urticária:

o Comum em crianças - entre $2,1 \%$ e $6,7 \%$.

o Manejo na infância semelhante a adultos com características específicas:

- Desencadeantes indutores

- Terapia farmacológica.

o Diagnóstico preciso é um pré-requisito essencial para um manejo bem sucedido.

\section{Definição de Urticária}

Presença de pápula com: prurido ou queimação, edema central, desaparecendo dentro de um período máximo de $24 \mathrm{~h}$, sem deixar lesão residual

Associada a angioedema que se caracteriza por sensação de formigamento ou dor, edema da derme e tecido subcutâneo profundo e resolução em até 72 h.

\section{Fisiopatologia}

Urticária resulta da ativação e liberação de vários mediadores de mastócitos na derme superficial. Basófilos, também foram identificados em biópsias lesionais. Entre os mediadores de liberação imediata se destaca a histamina, que causa prurido, vasodilatação e aumento da permeabilidade vascular. Outros vasodilatadores e mediadores quimiotáticos, são liberados, entre eles PAF, tromboxano, prostaglandinas e leucotrienos. No angioedema ocorre o mesmo processo na derme mais profunda e tecido subcutâneo.

O mastócito pode ser ativado por:

o Reações alérgicas mediada por IgE do tipo I ou imediatas 
- Aparece de minutos a duas horas após a exposição ao alérgeno, e são causas de urticária por medicamentos, alimentos e aditivos alimentares, picadas de insetos e picadas, látex e hemoderivados.

o Liberação direta de mediadores de mastócitos por:

o Ativação imune pela formação de imune-complexos e ou anafilotoxinas (C3a e C5a) decorrente da ativação do complemento. Ocorre principalmente em urticárias associadas a infecções.

o Certos medicamentos

- narcóticos (analgésico, opiáceos, dextran), relaxantes musculares (atracúrio, vecurônio, succinilcolina e curare também mediada por $\lg \mathrm{E}$ ), vancomicina (infusão rápida leva a rubor), meio de contrastes, frutas e plantas (urtiga possui histamina e mediadores que causam dor).

o Alimentos e plantas

- tomates, morangos e outros alimentos podem causar urticária generalizada ou urticária de contato.

\section{Classificação de Urticária}

Tipos principais de acordo com seus precipitantes e duração

1- urticária aguda,

2- urticária crônica

3- urticária física

4- outros tipos de urticária

$\square$ Exibem etiologias distintas e abordagens de manejo específicas

Lesões de urticária aguda e crônica são idênticos na aparência

Subtipos diferentes podem coexistir na mesma criança

\section{Urticária Aguda}

Duração de menos de 6 semanas

Auto-limitada

Tipo mais comum de urticária em crianças

Maioria é leve, mas pode evoluir para choque anafilático grave em minutos

\section{Causa de Urticária Aguda}

Identificada em $20 \%$ a $90 \%$

Causas mais comum

1- Infecções,

2- hipersensibilidade a drogas e

3- alimentar

$\square$ Às vezes há necessidade de combinação de desencadeantes para provocar lesão

\section{Infecções como desencadeante de Urticária Aguda}

Mais freqüente e potencialmente tratável 
Vias aéreas superiores, gastrointestinal e urinárias infecções silenciosas são discutíveis.

Sazonalidade de IVAS é semelhante à sazonalidade de urticária aguda

Tabela 1 - Agentes infecciosos e parasitas associados com urticária aguda

\begin{tabular}{l|l}
\hline Vírus & $\begin{array}{l}\text { Adenovírus, enterovírus, rotavírus, vírus sincicial respiratório, } \\
\\
\\
\text { Epstein-Barr, CMV , vírus da hepatite A, B ou C fase pré-ictérica, } \\
\text { manifestação inicial de HIV }\end{array}$ \\
Bactérias $\square$ & Estreptococos, Mycoplasma pneumoniae, Clamídia \\
Parasitas $\square$ Blastocystis hominis, Plasmodium falciparum, Ancylostoma, \\
\\
Strongyloides, Filaria, Echinococcus, Trichinella, Toxocara, \\
Fasciola, Schistosoma mansoni e Anisakis simplex (controverso)
\end{tabular}

Hipersensibilidade a fármacos como desencadeante de Urticária Aguda

$2^{a}$ principal causa

Antibióticos (beta-lactâmicos e outras classes) e AINEs (prescritos em infecções)

Papel pode ser superestimado

Confirmação do diagnóstico:

1- ensaios in vitro e/ou testes de cutâneos após avaliar risco/benefício

2- testes de provocação, baseado na história e drogas implicadas - avaliar risco/benéfico

Conduta: suspensão da droga e prescrição de medicamento alternativo, sem reatividade cruzada.

\section{Alergia alimentar como desencadeante de urticária aguda}

Menos de $7 \%$ da causa de urticária aguda.

Contato direto da pele (urticária de contato), inalação ou ingestão.

Urticária aguda é principal manifestação de alimentar IgE mediada

o Sintomas imediatos após a ingestão de alimentos (em>1 h)

- Exclusão de reação do tipo I é feita quando ocorre remissão da urticária em menos de $48 \mathrm{~h}$ após retirada do alimento suspeito.

Diagnóstico

1- dosagem sérica de IgE alérgeno-específica e / ou teste cutâneo com alérgenos alimentares suspeitos.

2- Provocação alimentar é o padrão ouro para o diagnóstico.

3- Alérgenos alimentares específicos $\rightarrow$ identificados e eliminados da dieta da criança.

Principais alimentos na tabela 2.

Tabela 2 - Alimentos associados com urticária aguda 


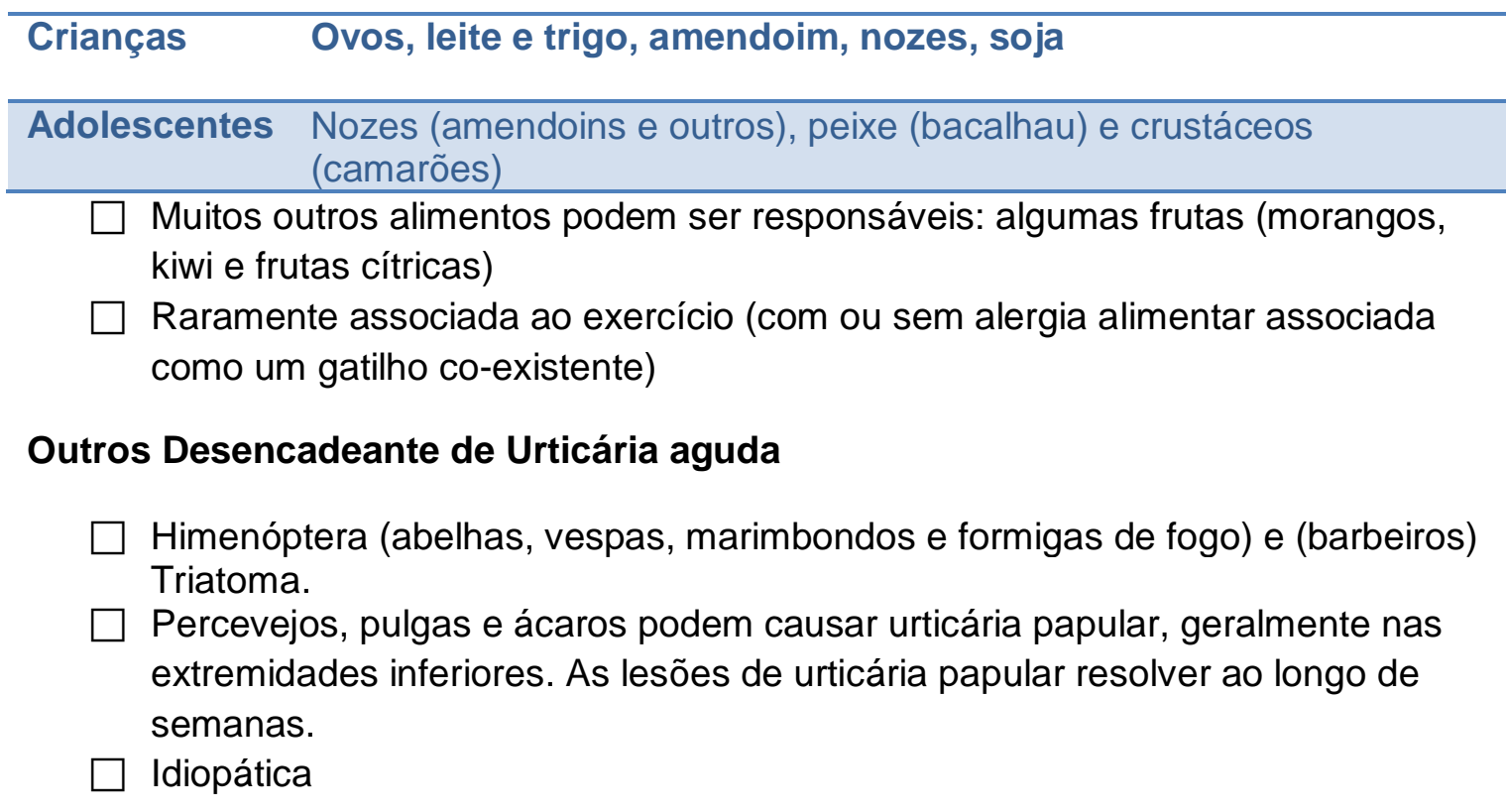

\section{Urticária Crônica}

Duração mais de seis semanas

Estudo espanhol com 917 crianças foi urticária foi encontrado em 5,9\%, sendo que destas $18 \%$ eram urticária crônica.

Causas

1- infecções

2- auto-imunidade

3- hipersensibilidade alimentar

4- outros agentes precipitantes

\section{Infecções como desencadeante de urticária crônica}

Associada a infecções recorrentes do trato respiratório e infecções urinárias Sinais e sintomas infecciosos devem ser avaliados durante a anamnese e exame físico e tratados adequadamente em todas as crianças com urticária crônica. Documentar infecções, avaliar a melhora ou remissão da urticária com o tratamento de infecções.

$\square$ Pesquisa mais completa é aconselhável em crianças com urticária crônica refratária e suspeita de infecção subjacente. (hemograma completo, VHS ou PCR)

$\square$ Urticária crônica pode ser multifatorial e não só infecciosas.

Principais agentes na tabela 3.

Tabela 3 - Agentes infecciosos e parasitas associados com urticária crônica

\begin{tabular}{ll}
\hline Vírus & vírus de Epstein-Barr \\
\hline Bactérias & estreptococos, estafilococos, Helicobacter pylori, e Escherichia coli \\
Parasitas & Blastocystis hominis, outras infestações parasitária \\
\hline
\end{tabular}




\section{Auto-reatividade como desencadeante de urticária crônica}

Ativação e desgranulação de mastócitos através de ativação de receptores para o complemento ou anticorpos para receptores de $\lg \mathrm{E}$ as prováveis etiologias. A urticária também pode ser uma manifestação de pacientes com doenças auto-imunes e se apresentar ou ocorrer esporadicamente.

\section{Urticária Auto-imune}

Auto-anticorpos para o receptor de IgE

Avaliada por critérios clínicos e imunológicos laboratoriais

o Teste in vitro: ensaio de libertação de histamina de basófilos e imunoensaio (Western blot ou teste imunoenzimático),

o Teste in vivo (ASST): teste cutâneo com soro autólogo

- Positividade indica presença de auto-anticorpos (ou outros fatores) no soro do paciente

- Não de deve realizar ASST de rotina, só após avaliação da gravidade, duração ou abordagem terapêutica

*Características clínicas, necessidade de medicação ou remissão urticária crônica semelhantes com ASST negativo ou positivo

\section{Doenças Auto-imunidade e Urticária Crônica}

Urticária mais grave ou que sem resposta ao tratamento padrão pode estar associada a doenças auto-imunes. Deve ser considerada, se sugerido pela história. As principais doenças auto-imune associadas com urticária são:

o Auto-imunidade tireoidiana - exames laboratoriais de hormônios da tireóide ou anticorpos não deve ser realizada de forma rotineira, mas se a história pessoal ou familiar da criança sugere disfunção da tiróide

o D. Celíaca

- pode ser subclínica, ser a causa ou doença associada, ocorre a remissão da urticária após dieta livre de glúten. Em pacientes com urticária crônica refratários, a doença celíaca foi diagnosticada em 5\%, e houve remissão completa da urticária em 5-10 semanas com uma dieta livre de glúten. Crianças sem urticária a doença celíaca ocorre em 0,67\%.

o Artrite idiopática juvenil, Síndrome de Sjögren, LES, diabetes tipo 1

\section{Hipersensibilidade alimentar como desencadeante de Urticária Crônica}

Alergia alimentar IgE-mediada é rara na urticária crônica em crianças São relatadas associações com pseudo-alérgenos, a saber:

o aditivos alimentares, agentes corantes e conservantes, glutamato monossódico e adoçante (sacarina / ciclamato).

o pseudo-alérgenos naturais, como compostos aromáticos encontrados em vegetais e outros alimentos (tomate e seus derivados), histamina, 
proteína com resíduo rico de salicilato. O corante amarelo urucum (anato) e o corante vermelho carmim têm sido documentados como causas de urticária e anafilaxia.

Manejo na suspeita de hipersensibilidade a alimentos e aditivos alimentares:

o Dietas sem pseudo-alérgenos pode ser benéfica para alguns pacientes.

- Dieta deve ser adaptada ao paciente, guiada pela história e documentadas.

- Confirmada por dieta de eliminação por pelo menos 3 semanas ( com supervisão nutricional para evitar deficiências nutricionais), seguido por testes de provocação oral (adaptadas ao paciente em particular e alimentos/aditivo suspeito. Pesar risco/benefício).

o Dietas muito rigorosas, com proibição de alimentos essenciais e potencialmente prejudiciais para a criança, não é aconselhável.

\section{Outros fatores precipitantes em Urticária Crônica}

Devem ser cuidadosamente considerados na anamnese e exame físico e se necessário, recomenda-se testes adicionais.

Medicamento não é precipitante comum em estudos pediátricos. Pode haver recorrência da urticária após a ingestão de alguns medicamentos.

$\square$ Malignidade - urticária pode também ser visto com doenças malignas, especialmente em urticária crônica de difícil controle e paraproteinemias por IgG e IgM. É necessário realizar história completa, exame físico e acompanhamento. Não há recomendação de triagem para neoplasias em crianças com urticária crônica espontânea.

\section{Urticária física}

Desencadeantes físicos são facilmente identificados na urticária crônica na infância

$\square$ É classificada em subtipos de urticária física de acordo com o gatilho:

1- Ao frio

2- Ao calor

3- Dermográfica

4- Colinérgica

5- Pressão tardia

6- Solar

7- Vibratória

Cada subtipo de urticária física é diagnosticado com a história e testes específicos

Manejo - evitar estímulo físico

\section{Urticária Dermográfica}

- Causa mais comum de urticária física, ocorre de forma isolada em 38\%, associada a outras formas em $70 \%$.

- Provocada por fricção/coçadura, aparecimento rápido, geralmente sem angioedema. 
- Idiopática ou $2^{\mathrm{a}}$ a infecções, infestações, drogas ou relacionadas à mastocitose sistêmica.

- Evitar roupas apertadas ou lã na pele de crianças

- Importante diferenciar de dermografismo, onde a pápula ocorre após atrito mínimo, sem prurido, mais frequente e não requer investigação ou tratamento.

\section{$\underline{\text { Urticária ao frio }}$}

- Frio induz lesões de urticária imediatamente após a exposição a objetos, ar ou fluidos frios ou a ingestão de alimentos frios (bebidas ou sorvetes)

- Atividades aquáticas - reações sistêmicas e risco de anafilaxia e afogamento. Anafilaxia ao frio ocorre em até $50 \%$ dos casos

- Maioria é idiopática ou pode ser associada a $2^{\mathrm{a}}$ a infecções virais (CMV e Hepatite C) ou crioglobulinemia

- Existem formas atípicas de urticária ao frio (hereditária ou adquirida) com prova de estimulação ao frio negativa e características imediatas incomuns, com reações sistêmicas ou prolongadas.

\section{Urticária Colinérgica}

- $2^{\circ}$ tipo mais comum

- Ocorrem minutos após aumento da temperatura do corpo, de forma passiva (banho quente) ou ativa (exercício). Caracterizada por pápulas com diâmetro inferior a $5 \mathrm{~mm}$.

\section{$\underline{\text { Urticária induzida pelo exercício }}$}

- Banho quente não provoca urticária e as pápulas são maiores do que $5 \mathrm{~mm}$.

- Anafilaxia induzida pelo exercício dependente de alimentos ocorre em:

o Adultos jovens e adolescentes,

- Até 30 minutos de exercício,

- Existem manifestações cutâneas e rápida progressão para reação sistêmica grave.

- Mediada por IgE: trigo (IgE específica para $\omega-5$ gliadina), outros cereais, mariscos, nozes, legumes, frutas frescas, leite e ovo.

o Alimento é tolerado na ausência de exercício

o Diagnóstico

- provocação oral isolada e teste ergométrico sem a ingestão do alimento suspeito por $4 \mathrm{~h}$

- teste de exercício após a ingestão de alimentos suspeitos

- alto risco de reações graves,

- sensibilidade do teste combinado é de $70 \%$

\section{Urticária Contato}

- Reações de hipersensibilidade imediata para proteínas exógenas e produtos químicos.

- Pode evoluir para manifestações sistêmicas, graves e com risco de vida

- Principais causas 
- Látex, em crianças com espinha bífida ou vários procedimentos cirúrgicos com contato com látex desde o início da vida.

o Síndrome pólen-fruta - urticária oral e peri-oral por contato direto da mucosa oral com alimentos é uma manifestação frequente de alergia alimentar em crianças.

o Produtos vegetais e resinas, frutas e vegetais crus ou frutos do mar crus, saliva animal.

\section{Diagnóstico de Urticária}

Anamnese e exame físico - chave para a identificação de fatores relevantes.

o História - Lesões individuais transitórias, que coçam, com duração de minutos a 24 horas. Desaparecem, sem deixar marcas, equimoses residuais (se não houver trauma por coçadura). Normalmente indolor.

- Distribuição - Qualquer local do corpo

- Morfologia - placas edematosas central, pápula e vermelhidão ao redor (surto). As lesões podem ser redonda, oval, ou serpiginoso, lesões anulares resultar de compensação central. Variam em tamanho (menor que um centímetro a vários centímetros de diâmetro)

Pode ser associado com angioedema

Evolui menos frequentemente para anafilaxia (reação com erupção progressiva, dificuldades respiratórias e comprometimento cardiovascular). As causas mais comuns de reações anafiláticas são: Alergia alimentar, drogas e picadas / mordidas de insetos.

\section{Investigações}

Extensa avaliação não é necessária na urticária aguda

Teste específico

o Realizado somente se fortemente sugerido pela história

- Considerar utilidade do resultado.

o A maior parte do tempo, o paciente será capaz de identificar a causa, principalmente na urticária aguda. (Tabela 4)

Tabela 4 - Causas subjacentes / desencadeantes e recomendações gerais de teste na urticária infância

\begin{tabular}{lll}
\hline $\begin{array}{l}\text { Tipo de } \\
\text { urticária }\end{array}$ & $\begin{array}{l}\text { Causas subjacentes/desencadeantes / subtipo } \\
\text { urticária }\end{array}$ & Recomendações gerais de teste \\
& Infecções (virais bacterianas ou parasitárias) & Nenhum recomendado \\
Urticária & Hipersensibilidade (alimentos, medicamentos) & Ou baseado na história (por exemplo, na \\
Aguda & Outros (ex. insetos, inalantes) & $\begin{array}{l}\text { suspeita de alergia IgE-mediada) } \\
\end{array}$
\end{tabular}




\begin{tabular}{|c|c|c|}
\hline \multirow{5}{*}{$\begin{array}{l}\text { Urticária } \\
\text { crônica }\end{array}$} & \multirow{3}{*}{$\begin{array}{l}\text { Infecções (virais bacterianas ou parasitárias) } \\
\text { Doenças auto-imunes (tiróide, d. celíaca, d. } \\
\text { tecido conjuntivo) }\end{array}$} & $\begin{array}{l}\text { Guiados por possíveis causas suspeitas } \\
\text { pela anamnese e exame físico. }\end{array}$ \\
\hline & & $\begin{array}{l}\text { Considerar hemograma completo, } \\
\text { VHS/PCR }\end{array}$ \\
\hline & & Exame de urina, função hepática (EUA) \\
\hline & Outro (hipersensibilidade alimentos, aditivos, & (5). \\
\hline & medicamentos; malignidade) & $\begin{array}{l}\text { Suspeita de etiologia específica, } \\
\text { laboratório e avaliação mais } \\
\text { aprofundada (EUA) (5). }\end{array}$ \\
\hline
\end{tabular}

\section{Dermográfica}

Frio

Urticária

física Colinérgica

Outros (calor, pressão tardia, solar, vibratória, exercício, aquagênica)
Teste de provocação para subtipo urticária física.

Se positivo, determinar o limiar de estimulação

Urticária dermográfica e frio hemograma completo VHS / PCR.

Excluir outras doenças, se suspeitas

\section{Manejo da Urticária}

\section{Etapas essenciais}

Identificação / prevenção / eliminação de desencadeantes e / ou causas subjacentes, única terapia potencialmente curativa.

Informação sobre como identificar as causas e formas de controle Manipulação da dieta não é indicada para todos os pacientes

Tratamento de alívio dos sintomas

o Compressas frias

o Anti-histamínicos para alivio do prurido (vide tabela 5 e 6).

o Anti-H1 de $2^{\mathrm{a}}$ geração são recomendados como terapia de $1^{\mathrm{a}}$ linha por diretrizes de Alergia e Dermatologia. Tem mínimo efeito sedativo, poucos efeitos anticolinérgicos e interações medicamentosas e requerem dosagem menos frequente em comparação com agentes de primeira geração.

o Anti-histamínico de $\mathbf{1}^{\mathrm{a}}$ geração - são lipofílicos e atravessam facilmente a barreira hemato-encefálica, causando sedação (diminuição do rendimento) e efeitos secundários anticolinérgicos (boca seca, diplopia, visão turva, retenção urinária, ou secura vaginal) que limita o uso. Os pacientes devem ser advertidos sobre estes efeitos adversos. Pode ser útil, se usado a noite especialmente quando combinado com um anti-histamínico $\mathrm{H} 1$ não sedativo durante o dia. Disponíveis em 
preparações parenterais quando um início de ação mais rápida é desejado (departamento de emergência).

o Corticóides, ocasionalmente um curso curto, por via oral, pode ser necessário para controlar os sintomas persistentes e graves. Não inibem a desgranulação dos mastócitos, mas pode suprimir mecanismos inflamatórios Nos casos mais graves, uma dose única de prednisolona oral pode ser considerada. Dose de 0,5 a $1 \mathrm{mg} / \mathrm{kg} /$ dia (máximo de $60 \mathrm{mg}$ por dia), com a diminuição gradual da dose durante cinco a sete dias. Corticosteróides tópicos não funcionam.

Pacientes com anafilaxia devem procurar departamento de emergência e uso de epinefrina. A recomendação de epinefrina auto-injetável deve ser considerada de acordo com história e desencadeantes.

Tabela 5 - Anti-histamínicos Orais de 2a geração licenciada para uso pediátrico

\begin{tabular}{|c|c|c|c|}
\hline Drogas & Apresentação & Dose diária criança & Dose diária adulto \\
\hline Bilastina $b$ & Comp. $20 \mathrm{mg}$ & $\geq 12$ a.: $20 \mathrm{mg} 1 \mathrm{vez} / \mathrm{d}$ & 20 mg 1 vez / dia \\
\hline Cetirizina* & $\begin{array}{l}\text { Comp. } 10 \mathrm{mg} \\
\text { Xarope } 1 \mathrm{mg} / \mathrm{ml}\end{array}$ & $\begin{array}{l}2-5 \text { a.: } 2,5 \mathrm{mg} 2 \text { vezes/d } \\
6-11 \text { a.: } 5 \mathrm{mg} 2 \text { vezes } / \mathrm{d} \\
\geq 12 \text { a.: } 10 \mathrm{mg} 1 \mathrm{vez} / \mathrm{d}\end{array}$ & $10 \mathrm{mg} 1 \mathrm{vez} / \mathrm{dia}$ \\
\hline Desloratadina* & $\begin{array}{l}\text { Comp. 5mg } \\
\text { Xarope 0,5 } \\
\mathrm{mg} / \mathrm{ml}\end{array}$ & $\begin{array}{l}1-5 \text { a.: } 1,25 \mathrm{mg} 1 \mathrm{vez} / \mathrm{d} \\
6-11 \text { a:: } 2,5 \mathrm{mg} 1 \mathrm{vez} / \mathrm{d} \\
\geq 12 \text { a.: } 5 \mathrm{mg} 1 \mathrm{vez} / \mathrm{d}\end{array}$ & $5 \mathrm{mg} 1 \mathrm{vez} / \mathrm{dia}$ \\
\hline Ebastina & $\begin{array}{l}\text { Comp. } 10 \mathrm{mg} \\
\text { Xarope } 1 \mathrm{mg} / \mathrm{ml}\end{array}$ & $\begin{array}{l}2-5 \text { a.: } 2,5 \mathrm{mg} 1 \mathrm{vez} / \mathrm{d} \\
\text { 6-11 a.: } 5 \mathrm{mg} 1 \mathrm{vez} / \mathrm{d} \\
\geq 12 \text { a.: } 10 \mathrm{mg} 1 \mathrm{vez} / \mathrm{d}\end{array}$ & $10 \mathrm{mg}$ ou $20 \mathrm{mg} 1 \mathrm{vez} / \mathrm{dia}$ \\
\hline Fexofenadina* & $\begin{array}{l}\text { Comp. } 60,120 \\
\text { e } 180 \mathrm{mg} \\
\text { Xarope } 6 \mathrm{mg} / \mathrm{ml}\end{array}$ & $\begin{array}{l}\text { 6-11 a.: } 30 \mathrm{mg} 2 \text { vezes /d \# } \\
\geq 12 \text { a.: } 120 \mathrm{mg} \text { de d ou } 180 \mathrm{mg} 1 \\
\text { vez / d }\end{array}$ & $120 \mathrm{mg}$ ou $180 \mathrm{mg} 1 \mathrm{vez} / \mathrm{dia}$ \\
\hline Levocetirizina & $\begin{array}{l}\text { Comp } 5 \mathrm{mg} \\
\text { Gotas } 1 \mathrm{ml} / \\
5 \mathrm{mg}\end{array}$ & $\begin{array}{l}2-5 \text { a: } 1,25 \mathrm{mg} \mathrm{d} 2 \text { vezes /d } \\
\geq 6 \text { a12 a: } 5 \mathrm{mg} 1 \mathrm{vez} / \mathrm{d}\end{array}$ & $5 \mathrm{mg} 1 \mathrm{vez} / \mathrm{dia}$ \\
\hline Loratadina & $\begin{array}{l}\text { Comp. } 10 \mathrm{mg} \\
\text { Xarope } 1 \mathrm{mg} / \mathrm{ml}\end{array}$ & $\begin{array}{l}\text { 2-11 a: } 5 \mathrm{mg} 1 \mathrm{vez} / \mathrm{d} \\
\geq 12 \text { a: } 10 \mathrm{mg} 1 \mathrm{vez} / \mathrm{d}\end{array}$ & $10 \mathrm{mg} 1 \mathrm{vez} / \mathrm{dia}$ \\
\hline Rupatadina & Comp. $10 \mathrm{mg}$ & $\geq 12$ a: $10 \mathrm{mg} 1 \mathrm{vez} / \mathrm{d}$ & $10 \mathrm{mg} 1 \mathrm{vez} / \mathrm{dia}$ \\
\hline
\end{tabular}


*Contra-indicado para crianças com menos de 2 anos de idade

Tabela 6 - Anti-histamínico de $1^{\text {aa }}$ geração

\begin{tabular}{|c|c|c|c|}
\hline Drogas & Apresentação & Dose diária para crianças & Dose diária para adultos \\
\hline Clorfeniramina & $\begin{array}{l}\text { Sol } 5 \mathrm{ml} / 2 \mathrm{mg} \\
\text { Comp. } 2 \text { e } 6 \mathrm{mg}\end{array}$ & $2 \geq$ a. $-0,15 \mathrm{mg} / \mathrm{Kg} / \mathrm{d}$ & 2 a $8 \mathrm{mg} / \mathrm{dia}$ \\
\hline Clemastina & $\begin{array}{l}\text { Sol 0,05 mg/ml, } \\
\text { Comp. } 1 \mathrm{mg}\end{array}$ & 3-5 anos: o, $5 \mathrm{mg} / \mathrm{Kg} / \mathrm{d}$ & 2 mg: 3 vez / dia \\
\hline Cipro-heptadina & $\begin{array}{l}\text { Sol } 2 \mathrm{mg} / 5 \mathrm{ml} \\
\text { Comp. } 4 \mathrm{mg}\end{array}$ & $\begin{array}{l}2 \geq \text { a. }-0,125 \mathrm{mg} / \mathrm{Kg} / \mathrm{dia} \\
\text { (não ultrapassar } 16 \mathrm{mg} \text { ) }\end{array}$ & 2-8 mg / dia 50 a 400mg? \\
\hline Hidroxizine & $\begin{array}{l}\text { Sol } 2 \mathrm{mg} / \mathrm{ml} \text {, } \\
\text { Comp. } 25 \mathrm{mg}\end{array}$ & $\begin{array}{l}>6 \mathrm{Kg} \\
1-2 \mathrm{mg} / \mathrm{Kg} / \mathrm{dia}\end{array}$ & $10 \mathrm{mg}$ ou $200 \mathrm{mg} / \mathrm{dia}$ \\
\hline Cetotifeno & $\begin{array}{l}\text { Comp. } 2 \mathrm{mg} \\
\text { Gotas } 1 \mathrm{mg} / \mathrm{ml} \\
\text { Xarope } 1 \mathrm{ml} / 5 \mathrm{ml}\end{array}$ & $\begin{array}{l}0,05 \mathrm{mg} / \mathrm{Kg} / \mathrm{dia} \\
2 \text { a } 6 \text { anos: } 2 \mathrm{mg} 2 x / \mathrm{dia}\end{array}$ & 1 a $2 \mathrm{mg} / \mathrm{dia}$ \\
\hline $\begin{array}{l}\text { Difenidramina } \\
\text { Benadryl }{ }^{\circledR}\end{array}$ & $\begin{array}{l}\mathrm{EV}, \mathrm{IM} \\
\text { Amp: } 50 \mathrm{mg} / \mathrm{ml}\end{array}$ & $\begin{array}{l}0,5-1,25 \text { mg / kg (até } 50 \\
\text { mg/dose) } \\
\text { IV / IM a cd } 6 \text { h. } \\
\text { Solução oral - } 5 \mathrm{ml}-12,5 \\
\text { mg }\end{array}$ & $\begin{array}{l}10 \text { a } 100 \text { mg: } 1 \text { vez / dia } \\
\text { Max 40mg/dia }\end{array}$ \\
\hline $\begin{array}{l}\text { Prometazina* } \\
\text { (Fenergan }{ }^{\circledR} \text { ) }\end{array}$ & $\begin{array}{l}\text { EV, IM, VO } \\
\text { comp. } 25 \mathrm{mg} \\
\text { Amp } \\
: 50 \mathrm{mg} / 2 \mathrm{ml}\end{array}$ & $0,2-0,5 \mathrm{mg} / \mathrm{kg} /$ dose $6-8 \mathrm{~h}$ & $10-25 \mathrm{mg}$ adulto \\
\hline
\end{tabular}

Indicações para a consulta do especialista:

Presença de doenças associadas ou com características sistêmicas (urticária vasculite ou urticária crônica como manifestação de outra doença)

$\square$ Urticária com grave risco de vida associado: alergia de amendoim, látex ou ovos

Má resposta a anti-histamínicos

Angioedema das vias aéreas

Urticária crônica (> 6 semanas)

Doenças Sistêmicas que cursam com urticária e diagnóstico diferencial de urticária 
Lesão urticariforme pode ser uma característica precoce de uma doença sistêmica. A urticária associada com doenças sistêmicas é geralmente recorrente, persistente, e relativamente difícil de tratar, e apresentam características clínicas específicas que podem ajudar no diagnóstico diferencial, como:

$\square$ Urticária-vasculite

Vasculite Cutânea de Pequenos

Vasculite - Henoch Schönlein

Mastocitose cutânea

Eritema multiforme

Deficiência de inibidor de C1 esterase

Artrite reumatóide juvenil

Pitiríase rósea

$\square$ Erupção exantemática (morbiliforme

$\square$ Picadas de insetos

$\square$ Eritema multiforme minor

$\square$ Reações induzidas por Plantas

Summary: urticaria is a disease that affects children with particularities in relation to diagnosis and treatment. Mostly occurs acutely, but chronic forms are also seen and pose a challenge both in identifying the cause as in management. In this review we provide helpful information for the etiologic diagnosis driving this disease, as well as its control.

Keywords: acute urticaria, chronic urticaria, physical urticaria, childhood

\section{Bibliografia:}

1- Pite H. et al.; Management of Childhood Urticaria: Current Knowledge and Practical Recommendations; Acta Derm Venereol 2013; 93: 500-508.

2- Marrouche N.\& Grattan C; Childhood urticaria; Curr Opin Allergy Clin Immunol 2012, 12:485-490

3- Sackesen et al: Etiology of Different Forms of Childhood Urticaria; Pediatric Dermatology Vol. 21 No. 2 102-108, 2004

4- Zuberbier, T; The Role of Allergens and Pseudoallergens in Urticaria JID Symposium Proceedings; Vol. 6, No. 2 November 2001

5- Bingham, C. O.; New onset urticaria; 2014 UpToDate 